\title{
Dutch standard for condition assessment of buildings
}

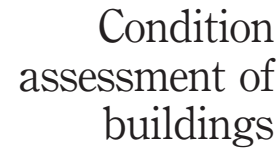

23

\begin{abstract}
Purpose - This paper aims to provide insight into the use of a standard for condition assessment. Design/methodology/approach - The paper is based on a literature review, an analysis of the development, content and practical use of the Dutch Standard for Condition Assessment of Buildings, and the findings of several research projects about condition assessment and maintenance planning by Dutch housing associations.

Findings - By using the standard for condition assessment, building inspectors can provide property managers with objective data about the condition status of building components. Aggregated condition data could be used for setting condition targets for built assets and for benchmarking. It is anticipated that as a result of the standardisation, condition surveys will become more reliable and as a consequence more popular among large-scale property owners.

Research limitations/implications - The standard has been introduced recently. At present there is little experience of the use of (aggregated) condition data for maintenance planning and benchmarking built assets.

Practical implications - The standard is a tool to assess the technical status of the properties to underpin the long-term maintenance expectations. Condition assessment is not meant for preparing the annual maintenance budget and planning of the work. Supplementary information is needed in the phase of preparing for the execution of remedial work.
\end{abstract}

Originality/value - This paper provides practical tools for condition assessment and maintenance planning.

Keywords Condition monitoring, Surface defects, Maintenance, Standardization, Buildings, The Netherlands

Paper type Research paper

\section{Introduction}

Building maintenance can be divided into three strategies: corrective, preventive and condition-based (Horner et al., 1997). Some authors refer to preventive maintenance as time-based maintenance, planned maintenance or cyclic maintenance. Condition-based maintenance is defined as preventive maintenance based on performance and/or parameter monitoring and the subsequent actions (CEN, 2001). Condition assessment, maintenance planning and performance control are key processes in condition-based maintenance. Technical data collected during a condition survey on-site is needed for building maintenance. All building components have to contend with performance loss through ageing, use, and external causes. Performance loss is measured in terms of defects ascertained. The defects are registered during a condition survey or condition assessment. In for instance the UK, client experiences of stock condition surveys has been far from satisfactory (Chapman, 1999). The practice of condition assessment by building inspectors yields variable results due to subjective perceptions of inspectors. Surveyor variability is defined as the situation where two or more surveyors,

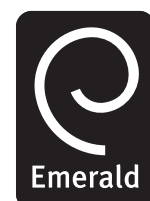

Structural Survey Vol. 27 No. 1, 2009 pp. $23-35$

(c) Emerald Group Publishing Limited 0263-080X 
SS

27,1

24

surveying the same building, arrive at very different survey decisions (e.g. Kempton et al., 2001, 2002). This variability is caused by a variety of factors such as previous experience, attitude to risk and, heuristics - the use of "rules of thumb", and biases - a leaning towards a particular opinion regardless of the available evidence.

The use of condition ratings of building components makes the technical status transferable between building inspectors and property managers. Property managers can exercise control over maintenance performance levels and maintenance costs. Is also makes the technical status transferable between the maintenance department and those involved in setting up the asset management.

\section{Research question}

This paper mainly discusses the process of condition assessment with the help of a standardised tool, namely the Dutch Standard for Condition Assessment of Buildings. The main research question is: How can the practice of condition assessment be standardised? The second research question is: How can large property owners and especially housing associations use condition data for maintenance planning and asset management purposes? The paper is based on a literature review, an analysis of the development, content and practical use of the Dutch Standard for Condition Assessment of Buildings and the findings of several published and non-published research projects by the author and others about condition assessment and maintenance planning by Dutch housing associations. This paper is comprised of the following parts: standardization, the condition assessment process, maintenance planning, condition aggregation, limitations in using the standard and conclusions. The translation of the Dutch standard is the responsibility of the author of this paper and not approved by The Netherlands Standardization Institute.

\section{Standardization}

Much national and international research has been carried out to achieve objectivity in the inspection process, especially for large-scale surveys, that should result in unambiguous information for maintenance and retrofit strategies (e.g. Abbott et al., 2007; Caccavelli and Genre, 2000; Damen Consultants et al., 1996; Damen et al., 1998; Jaggs and Palmer, 2000). As a result of several research projects and the use of the method by the Dutch Government Buildings Agency and in the Dutch Housing Quality Survey, the process of condition assessment using a six-point scale has become popular to property managers of housing associations and consultants in the Netherlands. A representative survey of Dutch housing associations shows that in 200390 per cent of the building inspectors registered the type of defects and the extent of these defects. One third one of the housing associations use condition ratings to record the technical status of the building components (Vijverberg, 2004). But, the condition assessment methods vary for the hierarchical classification of building components, classified defects and the use of condition parameters. Several condition assessment methods lead to variable condition rating results, while examining the same defects (Straub, 2003).

Standard for condition assessment of buildings

The different results of various condition assessment methods are not a drawback in practice. It is important that within an organisation all building inspectors handle their 
own method the same way. However, it is a handicap in the transfer of people and knowledge between property managers, consultants and maintenance contractors and, e.g. for benchmarking purposes within and between organisations. Standardization is seen as a tool to achieve uniformity in this. In 2002 the Dutch Government Buildings Agency took the initiative to standardise the condition assessment of building components, including building services. The aim of this standard is an objective assessment of the technical quality, to provide property managers with unambiguous, reliable information about the technical status based on assessed defects. The Standard for Condition Assessment of Buildings is aimed at:

- property owners, managers and administrators;

- tenants;

- consultants;

- contractors;

- inspectors of control bodies.

Application of the standard may include:

- visualisation of the physical condition;

- maintenance planning;

- prioritising of maintenance budgets;

- control of physical conditions;

- communication about the actual assessed physical condition and desirable condition (NEN, 2006).

Finally, the standard will comprise three parts:

(1) Methodology (NEN, 2006).

(2) List of faults (NEN, 2008).

(3) Aggregation methodology (NEN, 2009).

The focus of the standardised method is large scale property. Condition assessments should be performed visually by trained inspectors using some small equipment and measuring tools. The standard is limited to condition assessment. Maintenance planning and prioritising maintenance work are not included, although some examples for doing that are given. Maintenance activities are not related to the condition ratings.

\section{Six-point scale}

A six-point scale has been taken as the basis for the standardised method. The condition categories are of a chronological order that describe possibly occurring defects without references to remedial work. Table I gives the general descriptions of the condition ratings.

Pitt (1997) argues that whatever condition categories are adopted, it is essential that they are clearly defined and that data collectors are well trained to ensure data consistency and reliability. The use of a six-point scale is maybe special to The Netherlands. In large-scale property condition assessment methods often four or five-point scales are used. The scale formerly used in the English House Condition Survey has four categories: seriously defective or unfit, defective, just acceptable and satisfactory (Department of the Environment, 1991). The number of codes,

\section{Condition assessment of buildings}

25 
SS

27,1

26

characterising the state of degradation of building components in the European EPIQR-project (Energy Performance and Indoor Environment Quality, Retrofit) has been set at four: A, Good Condition, B, Slight degradation, C, Medium degradation and D, End of life span (Caccavelli and Genre, 2000). In South Africa a five-point scale has been proposed for the strategic management and maintenance of hospitals (Abbott et al., 2007). The condition rating is from 5 to 1: very good to very bad. Condition assessment ratings are related to maintenance actions, e.g. a very bad condition (5) involves replacement, and a fair condition (3) means repairs. Condition rating for the National Health Service in the UK is also based on a five-point scale (asset grading condition).

The use of a six-point scale might be remarkable from a psychological point of view. Since psychologists advise the use of an odd number of items in a judgements scale. Because of the limited human capacity for processing information the number of classes should be seven, plus or minus two. The six-point scale is a relic from the past and has to do with the scale division. The six-point scale is not linear but ordinal. A linear scale division presupposes a linear relationship between the conditions and the remaining service life of the building components. In reality the condition and service life of discrete building components and sets will differ. An ordinal scale division means that the values the variable can have can be classified, but their meaning is not univocal. A building component in condition 3 does not mean it is three times worse than a component in condition 1. Condition 1 of the six-point scale indicates the upper value of the scale. This absolute value cannot be exceeded. Condition 5 indicates the lower value of the scale. This bad condition is not an absolute value. Condition 6 has been added to distinguish a very bad situation, meaning that the component should already have been replaced.

\section{Condition assessment process}

The condition assessment process follows the pattern in Figure 1. The assessing of defects occurs first. Without this information one could not formulate maintenance activities and/or estimate costs. Subsequently the inspector passes through the following condition parameters: importance of defects, intensity of defects and extent of defects. The extent and the intensity of a defect combined with the importance of the defect lead to a condition rating, probably with a defect score as an intermediary product.

\section{Building components}

For an objective visual assessment, building inspectors need a clearly defined and hierarchical classification of building components. The list of faults (defects) uses the

Table I.

Condition rating

1

2

3

4

5

6

Source: NEN (2006)
General condition description

Excellent

Good

Fair

Poor

$\mathrm{Bad}$

Very bad 


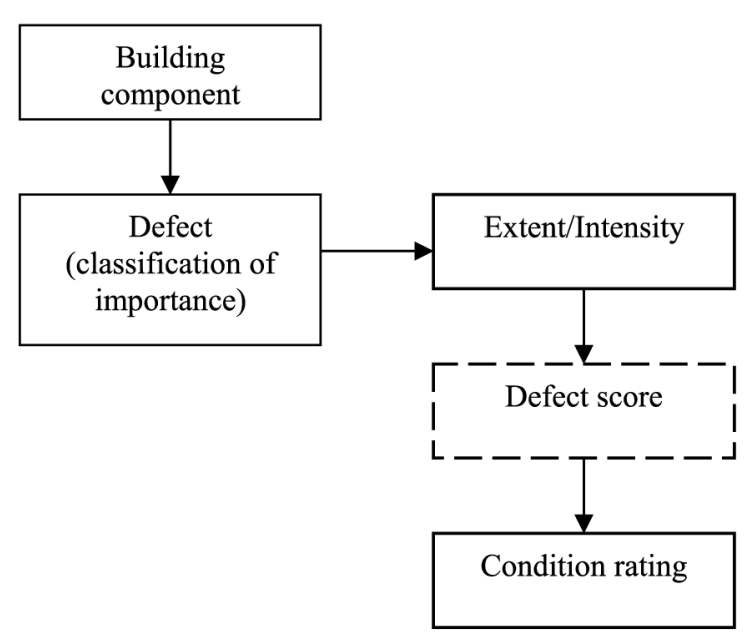

\section{Condition assessment of buildings}

\section{Source: NEN (2006)}

Figure 1. Condition assessment process

first four codes of the Dutch SfB-classification (NL SfB). This hierarchical classification directly influences the classification of the importance of defects. The building component list covers 80 to 90 per cent of the common building components in housing and real estate. In all other cases the given framework for importance rating should be used.

\section{Importance of defects}

The importance of the defect indicates to what extent it influences the functioning of building components. The standard classifies the importance of defects of distinct building components into minor, serious and critical (see Table II). Critical defects significantly threaten the function of the building component. Generally, material intrinsic defects like corrosion and wood rot, defects that threaten the building structure, e.g. stability and distortion, and "functional defects", are weighted as critical defects. Functional defects are those that are already associated with a failure. Serious defects are gradually damaging the performance of building components, for example defects in the material surface. Defects to the finishes, for example coatings, are classified as minor defects. Table III gives an example of the listed defects for windows and doors.

\section{Intensity of defects}

The intensity of defects strongly influences the condition of building components. The intensity of defects deals with the degradation process. Ageing defects like material intrinsic defects and defects involving the material surface, e.g. wear and soiling, develop over a certain period and will occur in several intensities. But defects caused by calamities, for instance glass breakage, just occur in one stage. The intensity rating has been the subject of much discussion in the standardisation committee. Finally, it was decided to use three intensity classes (Table IV). The list of faults determines if intensities are applicable for a building component. 
SS

27,1

$28 \quad$ Serious

Minor

\begin{tabular}{lll}
\hline Importance & Type & Explanation \\
\hline Critical & Basic functional & Critical defects harm directly the \\
& Basic constructional & function of a building component
\end{tabular}

Material intrinsic

Basic quality of key components

Minor functional

Minor constructional

Material surface

Basic quality and ageing of secondary components

Maintenance $^{\mathrm{a}}$

Finishing

Basic quality and ageing of tertiary

components

Deterioration $^{\mathrm{b}}$
Serious defects mean degradation of a building component without directly harming its function

Minor defects do not harm the function of a building component

Notes: ${ }^{\text {a }}$ Maintenance actions meant to keep the building component running were not executed, e.g. cleaning and legal tests; ${ }^{\mathrm{b}}$ condition assessment based on the theoretical component lifetime; this may

Table II. be applied if the condition cannot be assessed visually

Framework for defects

Source: NEN (2006)

Extent of defects

Besides knowledge about the intensity of defects, knowledge about the extent of defects is needed to assess the condition. Methodological questions arise about how many classes are manageable for building inspectors and how many classes are useful to link maintenance activities to the extent of defects in the policy making process. Clearly, to estimate the extent and chose the appropriate class is difficult, even for more experienced building inspectors. Obviously difficulties doing so also depend on the defect involved. One may differentiate general ageing defects normally covering the whole building component from localised defects. In the case of general ageing defects the intensity of a defect corresponds with the condition. The standard distinguishes five extent classes (Table V).

\section{Condition ratings}

The extent and the intensity of a defect combined with the importance of the defect lead to a condition rating. Tables VI-VIII give the matrices for respectively, critical, serious and minor defects.

Building components may show more than one defect. For this reason the standard gives two options of how to calculate a resulting condition rating. Another given option is to use a "defect score" based on the intensity and extent of a defect (Figure 1). A registration of defect scores is advised to monitor the development of a defect between subsequent condition surveys.

\section{Maintenance planning}

Just as with the collection of survey data, the decision-making process for planned maintenance holds subjective elements and often is not transparent. Condition-based maintenance can be seen as a tool to implement a desired differentiation of the technical quality of buildings by formulating performance levels. Varying performance 


\begin{tabular}{lll}
\hline Importance & Type & Defects \\
\hline Critical & Basic functional & Sealants defect \\
& Be ajar & Leakages \\
& Basic constructional & Cramps defect \\
Material intrinsic & Wood rot \\
& Moisture retention \\
& Capillary moisture absorption \\
& Cracks \\
& Cold bridges \\
& Condensation \\
& Basic quality of key & Wrong use of materials \\
& Failing drainage constructive parts \\
& Sharp edges jambs and sills \\
& Minor constructional & Distortion \\
& Missing parts \\
& Connections undone \\
& Failing stiffness and stability \\
& Mechanical damages \\
& Material surface & Ironmongery defects \\
Basic quality and ageing & Failing width windows \\
& of secondary components & Failing outline \\
& Failing putty and sealants glazing and panels \\
& Non-professional repairs \\
& Algal growth, moss \\
& Finishing & Pollution, surface deposit \\
& Discoloration \\
Minor & Failures secondary fastening \\
& Failures element parts \\
& Defects connections frames and wall &
\end{tabular}

Source: NEN (2008)

\section{Condition assessment of buildings}

29

Table III. Defect list window frames, door frames, windows and doors

\begin{tabular}{|c|c|c|c|}
\hline Intensity class & Name & Description & \\
\hline Intensity 1 & Low & The defect is hardly visible & \\
\hline Intensity 2 & Middle & The defect is progressing & \\
\hline Intensity 3 & High & The defect cannot progress any further & Classification of intensity \\
\hline Source: NEN (2006) & & & of defects \\
\hline
\end{tabular}

\begin{tabular}{lll}
\hline Extent class & Percentage & Description \\
\hline Extent 1 & $<2$ & The defect occurs incidentally \\
Extent 2 & $2-10$ & The defects occurs locally \\
Extent 3 & $10-30$ & The defects occurs regularly \\
Extent 4 & $30-70$ & The defects occurs frequently \\
Extent 5 & $\geq 70$ & The defect occurs generally
\end{tabular}

Source: NEN (2006)

Table V. Classification of extent of defects 
SS

27,1

30

levels is advisable in the case of a diverse portfolio and if the maintenance management system easily provides possibilities to do so. This might be the case for Dutch housing associations that do not focus solely on the production and management of cheap and decent dwellings, with only a limited differentiation in rents, tenure, target groups and quality. However, housing associations acknowledge that the technical quality is just one aspect of quality (e.g. Straub, 2002; Straub and Vijverberg, 2004). The technical quality is an important aspect if the housing estate strategy is consolidation. This is the case for larger parts of the housing stock of housing associations.

\section{Maintenance performance levels}

Formulating maintenance performance levels in planned maintenance involves deliberation about maximum performance loss, appropriate maintenance activities and the available financial means. Maintenance activities can be distinguished according to type (cleaning, repair and replacement), the part of the building component to which an activity applies, the specification of materials, the quantity of the work, the frequency of short cyclical preventive maintenance actions and the nature of an activity (preventive or corrective). Maintenance performance levels can be based on the minimum condition of building components after executing maintenance work (see Figure 2). Maintenance managers are able to set condition targets of building

Table VI.

Matrix of resulting condition ratings for critical defects

\begin{tabular}{lccccc}
\hline & & \multicolumn{5}{c}{ Extent } \\
Intensity & $<2 \%$ & $2 \%-10 \%$ & $10 \%-30 \%$ & $30 \%-70 \%$ & $\geq 70 \%$ \\
\hline 1 Low & 1 & 1 & 2 & 3 & 4 \\
2 Middle & 1 & 2 & 3 & 4 & 5 \\
3 High & 2 & 3 & 4 & 5 & 6
\end{tabular}

Source: NEN (2006)

\begin{tabular}{lccccc}
\hline & & \multicolumn{4}{c}{ Extent } \\
Intensity & $<2 \%$ & $2 \%-10 \%$ & $10 \%-30 \%$ & $30 \%-70 \%$ & $\geq 70 \%$ \\
\hline 1 Low & 1 & 1 & 1 & 2 & 3 \\
2 Middle & 1 & 1 & 2 & 3 & 4 \\
3 High & 1 & 2 & 3 & 4 & 5
\end{tabular}

Source: NEN (2006)

Table VII.

Matrix of resulting condition ratings for serious defects

\begin{tabular}{lccccc}
\hline Intensity & $<2 \%$ & $2 \%-10 \%$ & $\begin{array}{r}\text { Extent } \\
10 \%-30 \%\end{array}$ & $30 \%-70 \%$ & $\geq 70 \%$ \\
\hline 1 Low & 1 & 1 & 1 & 1 & 2 \\
2 Middle & 1 & 1 & 1 & 2 & 3 \\
3 High & 1 & 1 & 2 & 3 & 4
\end{tabular}

Table VIII.

Matrix of resulting condition ratings for minor defects

Source: NEN (2006) 


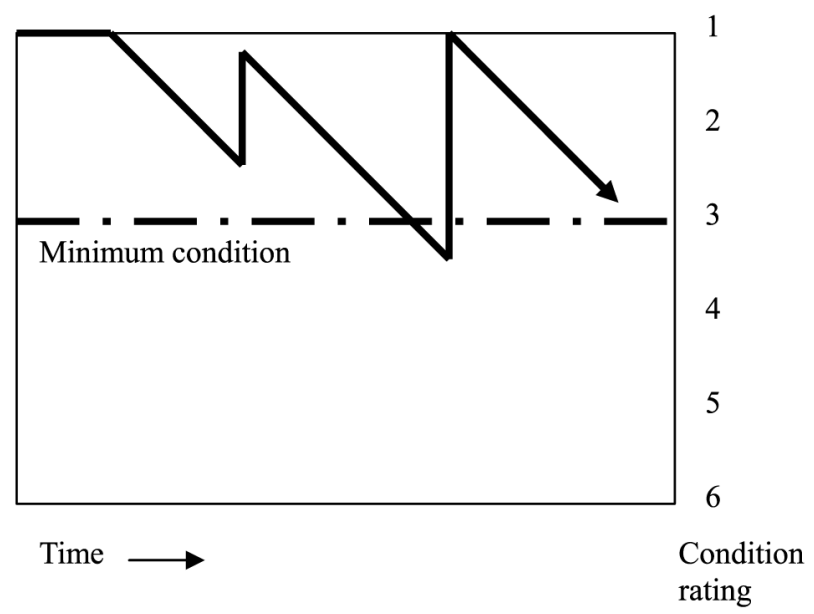

\section{Condition assessment of buildings}

Figure 2.

Maintenance planning using condition targets

components by forecasting the condition status of components after executing maintenance activities, dealing with more and less acceptable remaining defects. Some Dutch housing associations apply this method.

To work efficiently and effectively the performance of a building component after executing maintenance work should be clear. However, knowledge about maintenance activities and performance recovery is scarce. The condition of building components after partial replacements, repairs and cleaning is not clear for most technical managers of Dutch housing associations (Straub, 2001). After an integral replacement of the component the condition status will be as new (condition rating 1). In case of partial replacements and repairs the condition gap before and after the activity is insecure. The new condition depends on the solved defects at that particular moment of time. Hermans (1995) found that cleaning and repainting of surfaces does not influence the technical performance of substrates. The degradation will just process more gradually. Nevertheless, the aesthetic performance of a surface improves. Through functional material modification performance alterations take place: the characteristics of the building component change and the original performance capacity increases.

\section{Priority setting}

An important sub process of maintenance planning is prioritising maintenance work. Maintenance management systems should enable users to calculate maintenance performance levels and priority setting of maintenance work dealing with the risks of failure of components. Until 2000 most maintenance management systems were lacking possibilities to calculate alternative maintenance strategies and maintenance performance levels in planned maintenance. The systems just supported the tuning of the "maintenance stock" for the available budget by setting priorities. Built asset maintenance is seen as a cost burden and not as a way to improve the value of built assets (Jones and Sharp, 2007).

Normally, maintenance work needed to secure safety performance has precedence over work just for aesthetic or sustainable reasons. The initial year of the latter work will be delayed. Shen and Spedding describe a multi-attribute model for priority setting in planned maintenance of real estate (Shen and Spedding, 1998). Others describe 
SS

27,1

32

models for priority-setting of maintenance work by risks (e.g. Horner et al., 1997; Loy and Coleman, 2006; Pitt, 1997). Loy and Coleman (2006) argue that risks, as related to the functional operation of buildings, generally fall into three interrelated categories: business, environment and health and safety. They link consequence grading criteria to condition rating. Horner et al. (1997) outline a decision diagram using similar risk categories, using significant items. Significant items are those whose failure will affect health, safety, environment or utility (including cost). The Dutch Government Buildings Agency uses a risk-priority matrix in tuning the annual maintenance stock for the available budget. The matrix has been included as an appendix of the standard. The risks of defects of building components that are not solved are rated on a three-point scale. The risk categories are rated beforehand (see Figure 3).

\section{Condition aggregation}

Several Dutch housing associations and other property owners of large building stocks, e.g. the Government Buildings Agency and the Ministry of Defence want to use aggregated condition data for their asset management. Aggregated data is important management information for property and facility managers for monitoring, benchmarking and budget allocation purposes. Besides, aggregated condition data can be used for setting condition targets of buildings and housing estates.

The forthcoming third part of the Standard for Condition Assessment of Buildings will describe the methodology for the aggregation of condition ratings. Aggregating condition ratings means weighing the technical status of a building component against the other building components of a building. In the proposed method the weighted average of building components being part of a main component is first determined. Main components are for example facades, roofs, windows and doors, balconies and walkways and heating. The weights are diverted from the hierarchical levels of building components used in the Dutch Housing Quality Survey 2000 "KWR 2000". This means that construction parts count for 4, finishes and facilities count for 2 and paintwork counts for 1 . For example in case of external walls the condition of the brickwork counts for 4, the condition of exterior staircases (facilities) and plasterwork (finishes) counts for 2 and the condition of the paintwork counts for 1 . Second, the weighted average of main components of the housing estate is determined. The weights are diverted from the financial share in the replacement costs of the building, based on data of the KWR 2000.

Figure 3.

Risk-priority matrix

\begin{tabular}{|c|c|c|c|c|c|c|c|c|c|}
\hline \multirow[t]{2}{*}{ Risk } & \multicolumn{9}{|c|}{\begin{tabular}{|l|} 
Priority \\
\end{tabular}} \\
\hline & 9 & 8 & 7 & 6 & 5 & 4 & 3 & 2 & $\mathbf{1}$ \\
\hline \multicolumn{10}{|c|}{ Safety and health } \\
\hline \multicolumn{10}{|c|}{ Cultural and historical value } \\
\hline \multicolumn{10}{|c|}{ Utility and business } \\
\hline \multicolumn{10}{|c|}{ Consequence damage ${ }^{a}$} \\
\hline \multicolumn{10}{|c|}{$\begin{array}{l}\text { Increase of response } \\
\text { maintenance }\end{array}$} \\
\hline Aesthetics & & & & & & & & & \\
\hline
\end{tabular}

a further deterioration in the assessed or other components

Source: NEN (2006) 
In 2006 a case study indicated that the relationship between the aggregated condition ratings and the maintenance costs recorded in long-term maintenance planning is not univocal. Also the relationship between the maintenance costs and condition improvement - aggregated condition ratings before and after maintenance - is not clear. The main reason for this is the fact that the aggregation of condition ratings of building components comprises all building components, including components that do not need maintenance work within the exploitation period. For example generally occurring defects of the material surface with a low intensity will lead to a condition rating 3 (Table VI). Because of this weak relationship, two indicators for aggregated condition ratings will be developed: the calculated condition index, including all building components, and a maintenance index, without building components that normally will not be replaced during their lifetime and/or not be included in the long-term maintenance planning.

\section{Limitations in using the standard}

Condition assessment according to the standard should be used as a strategic management tool. The standard is a tool to assess the technical status of the properties to underpin the long-term maintenance expectations. Condition assessment is not meant for preparing the annual maintenance budget and planning of the work. Supplementary information is needed in the phase of preparing the execution of remedial work. Supplementary information might be the precise location of the defects and causes of defects to take adequate maintenance actions. The condition survey could be executed every three, four or five years. This is kept optional for the building owner.

Another limitation of the standard might be the fact that the condition assessment methodology and condition parameters of the standard are meant for the assessment of large-scale property. Condition assessment for individual homes is something else. However, e.g. home-buyer surveys are dealing with similar problems, as a poor standard of recognition of defects or potential defects (e.g. Hollis and Bright, 1999). Hollis and Bright suggest a high rate of sub-standard reporting for residential surveys too. In the Netherlands a standardization process for individual home surveys started in 2007.

The introduction of standard lists of defects, condition parameters and condition ratings could mean a clear break of the common working processes of building inspectors. Building and facility managers may doubt the benefits of a new method and especially the willingness and skills of their inspectors to work in that way. Experience shows that well-trained inspectors are able to manage condition surveys. The most difficult part is to forget about the old way of thinking and working. Well-educated and/or certified building inspectors should have enough knowledge and experience about elements, defects and remedial work. Nevertheless, it takes a lot of effort and time to use it in a different way: register the found situation and separately choose for maintenance activities. Maintenance managers have to evaluate training needs for their surveyors.

\section{Conclusions}

The standard for condition assessment is a useful tool for the inspection of large-scale properties. Building inspectors can provide property managers with objective data about the condition status of building components. Detailed surveyor manuals and the eyes of well-educated and experienced building inspectors remain important in getting 
SS

27,1

34 condition data. To make the use of the standard more reliable there might be a need for references of the listed defects and intensities by examples of pictures. The use of advanced performance measurements, sensor technology and intelligent decision support systems to monitor and report on changes in the performance of building components is still in its infancy. Moreover performance profiles of building components depend on the local circumstances. If inspectors are made responsible for the choice of maintenance activities at-site based on condition data, they need good instructions how to do that including a standard list of activities. A more objective approach would be to opt for selection of maintenance activities by a planning department at the office.

The assessment and setting of priorities for planned maintenance work is a way to tackle problems of shortage of maintenance funds. In addition to this, using the condition scale in the planning process gives the opportunity to vary the performances of building components. Maintenance performance levels can be based on the minimum condition of building components after executing maintenance work. In this approach assessed defects and condition ratings on one hand and acceptable defects and conditions ratings after executing maintenance work on the other hand, are steering instruments in the maintenance planning process.

It is to be expected that as a result of the standardisation, condition surveys will become more reliable and as a consequence more popular among housing associations and other large-scale property owners. Building inspectors can be trained in using one method for all situations. It makes the data also suitable for asset management and benchmarking purposes.

\section{References}

Abbott, G.R., McDuling, J.J., Parsons, S. and Schoeman, J.C. (2007), "Building condition assessment: a performance evaluation tool towards sustainable asset management", Proceedings of the CIB World Building Congress 2007, Cape Town, CIB, Rotterdam, pp. 649-62.

Caccavelli, D. and Genre, J.L. (2000), "Diagnosis of the degradation state of building and cost evaluation of induced refurbishment works", Energy and Buildings, Vol. 31 No. 2, pp. 159-65.

CEN (2001), EN 13306 Maintenance Terminology, CEN, Brussels.

Chapman, K.P. (1999), "Dissatisfaction with stock condition surveys in social housing", Structural Survey, Vol. 17 No. 4, pp. 211-5.

Damen Consultants et al. (1996), Brite Euram Project 4213 Condition Assessment and Maintenance Strategies for Building and Building Components, Damen Consultants, Rotterdam.

Damen, T., Quah, L.K. and van Egmond, H.C.M. (1998), "Improving the art and science of condition-based maintenance systems", in Quah, L.K. (Ed.), Proceedings of the CIB WO7O Symposium, The Way Ahead into the Millennium, Singapore, McGraw-Hill, Singapore, pp. 141-8.

Department of the Environment (1991), English House Condition Survey, HMSO, London.

Hermans, M.H. (1995), Deterioration Characteristics of Building Components: A Data Collection Model to Support Performance Management, TU Eindhoven, Eindhoven.

Hollis, M. and Bright, K. (1999), "Surveying the surveyors", Structural Survey, Vol. 17 No. 2, pp. 65-73. 
Horner, R.M.W., El-Haram, M.A. and Munns, A.K. (1997), "Building maintenance strategy: a new management approach", Journal of Quality in Maintenance, Vol. 3 No. 4, pp. 273-80.

Jaggs, M. and Palmer, J. (2000), "Energy performance indoor environmental quality retrofit a European diagnosis and decision making method for building refurbishment", Energy and Buildings, Vol. 31 No. 2, pp. 97-101.

Jones, K. and Sharp, M. (2007), "A new performance-based process model for built asset maintenance", Facilities, Vol. 25 Nos 13/14, pp. 525-35.

Kempton, J., Alani, A. and Chapman, K. (2002), "Surveyor variability in educational stock surveys - a lens model study”, Facilities, Vol. 20 Nos 5/6, pp. 190-7.

Kempton, J., Nichol, S., Anumba, C. and Dickens, J. (2001), "Surveyor variability in large-scale house condition surveys”, Structural Survey, Vol. 19 No. 4, pp. 156-62.

Loy, H.M. and Coleman, P. (2006), "A 21st century approach to the condition surveying of building services systems”, Journal of Building Appraisal, Vol. 2 No. 2, pp. 161-70.

NEN (2006), NEN 2767 Conditiemeting van bouw- en installatiedelen - Deel 1: Methodiek (Condition Assessment of Building and Installation Components - Part 1: Methodology), NEN, Delft (in Dutch).

NEN (2008), NEN 2767 Conditiemeting van bouw-en installatiedelen - Deel 2: Gebrekenlijsten (Condition Assessment of Building and Installation Components - Part 2: List of Faults), NEN, Delft (in Dutch).

NEN (2009), NEN 2767 Conditiemeting van bouw-en installatiedelen - Deel 3: Conditieaggregatie (Condition Assessment of Building and Installation Components - Part 3: Aggregation of Condition Scores), NEN, Delft (in Dutch).

Pitt, T.J. (1997), "Data requirements for the prioritization of predictive building maintenance", Facilities, Vol. 15 Nos 3/4, pp. 97-104.

Shen, Q. and Spedding, A. (1998), "Priority setting in maintenance - practical issues in using the multi-attribute approach", Building Research \& Information, Vol. 26 No. 3, pp. 169-80.

Straub, A. (2001), Technisch beheer door woningcorporaties in de 21e eeuw. Professioneel, klantgericht en duurzaam (Technical Management by Housing Associations in the 21st Century), Delft University Press, Delft (in Dutch).

Straub, A. (2002), "Strategic Technical management of housing stock: lessons from Dutch housing associations", Building Research \& Information, Vol. 30 No. 5, pp. 372-81.

Straub, A. (2003), "Using a condition-dependent approach to maintenance to control costs and performances", Journal of Facilities Management, Vol. 1 No. 4, pp. 380-95.

Straub, A. and Vijverberg, G. (2004), "New strategies for housing quality improvement by Dutch landlords", Open House International, Vol. 29 No. 3, pp. 38-45.

Vijverberg, G. (2004), "Strategic housing stock policy and maintenance management practise in Dutch social housing", in Then, D.S.S., Jones, K. and Hinks, J. (Eds), Proceedings of the CIB W070 Symposium, Human Elements in Facilities Management - Understanding the Needs for Our Customers, Hong Kong, CIB, Rotterdam, pp. 337-46.

\section{Corresponding author}

Ad Straub can be contacted at: a.straub@tudelft.nl

\footnotetext{
To purchase reprints of this article please e-mail: reprints@emeraldinsight.com
} Or visit our web site for further details: www.emeraldinsight.com/reprints

\section{Condition assessment of buildings}

